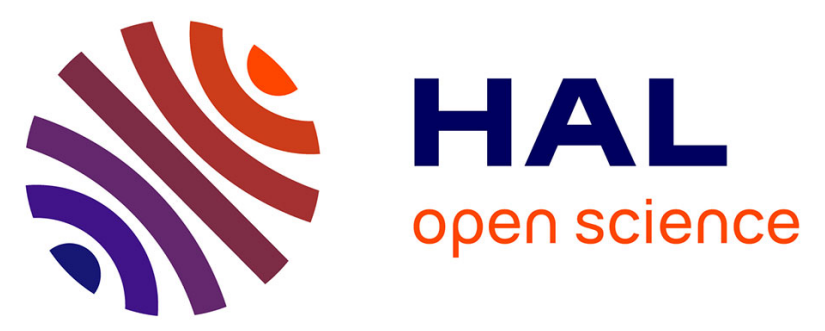

\title{
Characterization of rickettsial adhesin Adr2 belonging to a new group of adhesins in $\alpha$-proteobacteria
}

\author{
Manohari Vellaiswamy, Malgorzata Kowalczewska, Vicky Merhej, Claude
} Nappez, Renaud Vincentelli, Patricia Renesto, Didier Raoult

\section{- To cite this version:}

Manohari Vellaiswamy, Malgorzata Kowalczewska, Vicky Merhej, Claude Nappez, Renaud Vincentelli, et al.. Characterization of rickettsial adhesin Adr2 belonging to a new group of adhesins in $\alpha$-proteobacteria. Microbial Pathogenesis, 2011, 50 (5), pp.233-242. 10.1016/j.micpath.2011.01.009 . hal-02107132

\section{HAL Id: hal-02107132 \\ https://hal.science/hal-02107132}

Submitted on 17 Jun 2021

HAL is a multi-disciplinary open access archive for the deposit and dissemination of scientific research documents, whether they are published or not. The documents may come from teaching and research institutions in France or abroad, or from public or private research centers.
L'archive ouverte pluridisciplinaire HAL, est destinée au dépôt et à la diffusion de documents scientifiques de niveau recherche, publiés ou non, émanant des établissements d'enseignement et de recherche français ou étrangers, des laboratoires publics ou privés. 


\title{
Characterization of rickettsial adhesin Adr2 belonging to a new group of adhesins in $\alpha$-proteobacteria
}

\author{
Manohari Vellaiswamy ${ }^{\mathrm{a}}$, Malgorzata Kowalczewska ${ }^{\mathrm{a}}$, Vicky Merhej ${ }^{\mathrm{a}}$, Claude Nappez ${ }^{\mathrm{a}}$, \\ Renaud Vincentelli ${ }^{\mathrm{b}}$, Patricia Renesto ${ }^{\mathrm{c}}$, Didier Raoult ${ }^{\mathrm{a}, *}$ \\ a Université de la Méditerranée, Unité des Rickettsies, URMITE CNRS-IRD, Faculté de Médecine, 27 Bd Jean Moulin, 13385 Marseille cedex 05, France \\ ${ }^{\mathrm{b}}$ AFMB UMR 6098, CNRS, Universités Aix-Marseille I E' II, 163 Avenue de Luminy, 13288 Marseille cedex 9, France \\ ${ }^{\mathrm{c}}$ Unit of Virus Host Cell Interactions, UVHCI, UMI 3265 UJF-EMBL-CNRS, 6 rue Jules Horowitz, 38042 Grenoble cedex 9, France
}

\begin{abstract}
Background: Rickettsia prowazekii is the etiological agent of epidemic typhus and is an obligate intracellular bacterium that grows as a parasite freely within the cytoplasm of a eukaryotic host cell. Previous studies have shown that rOmpA and $\mathrm{rOmpB}$ which belong to the family of rickettsial cell surface antigens are involved in vitro in the adhesion of Rickettsiae to epithelial cells. Recently, two putative rickettsial adhesins have been identified using high resolution 2D-PAGE coupled with mass spectrometry. In this study, we further characterize and describe the adhesin Adr2 from $R$. prowazekii.

Methodology/Principal findings: Using an overlay assay coupled with mass spectrometry two adhesins, Adr1 (RP827) and Adr2 (RP828), were identified from the $R$. prowazekii proteome Recombinant $R$. prowazekii Adr2 was expressed through fusion with Dsbc in Escherichia coli, purified and concentrated, thus allowing production of specific monoclonal antibodies, as confirmed by western blot assays. Finally, inhibition of rickettsiae-induced cytotoxicity with monoclonal anti-Adr2 antibody has showed a greatest impact on bacterial cell entry at $8 \mathrm{~h}$ post-infection (ca50\%) and then decreased progressively to attempt $18 \%$ of inhibition at day 7. These, correlated to the inhibition of rickettsiae-induced cytotoxicity with monoclonal anti-rOmpB antibody. Thus, Adr2 is sufficient to mediate $R$. prowazekii entry into the cell at early stage of mammalian cell infection.

Conclusions: Our results suggest that $R$. prowazekii Adr2 could be the main actor promoting the entry of rickettsiae into the host cells. The present study opens the framework for future investigations for better understanding of the Adr2 -mediated mechanisms involved in adhesion/invasion or intracellular survival of $R$. prowazekii.
\end{abstract}

\section{Introduction}

Rickettsia prowazekii is the etiological agent of epidemic typhus. This bacterium is an obligate intracellular parasite that grows freely within the cytoplasm of its eukaryotic host cell rather than in phagosomes or phagolysosome [1]. R. prowazekii can be isolated from shell vial cell cultures, which has replaced classic animal- and/ or embryonated egg-based culture methods [2,3]. The pathogen exhibits a slow generation time $(8-12 \mathrm{~h})$, undergoes steady multiplication and lyses the host cell by releasing hundreds of infectious bacteria [3]. Understanding the mechanisms involved in

\footnotetext{
* Corresponding author. Unité des Rickettsies, IRD CNRS UMR 6236, Faculté de Médecine, 27 Bd Jean Moulin, 13385 Marseille, France. Tel.: +33 (0) 491324480 fax: +33 (0) 491387772

E-mail address: didier.raoult@gmail.com (D. Raoult).
}

this unique intracytoplasmic parasitism was the goal of current study.

Bacterial cell surface proteins are involved in host-parasite interactions and are targeted by the adaptive response of the host immune system [4]. Adhesion is a key step for bacterial invasion of host tissues, and adhesins are bacterial surface proteins that recognize receptors on host cells. The expression of various genes during adhesion can activate the pathogenic process [5]. Proteins as well as structural organelles on bacterial surface mediate adhesion. The bacterial components may be capsule, lipopolysaccharide, toxins and adhesins.

The $R$. japonica rOmpB autotransporter proteins function in rickettsial adherence to and invasion of Vero cells [6]. These proteins belong to a large family of outer membrane proteins known as the surface cell antigen (Sca) family [7]. Rickettsial entry into the host cell is mediated by the rOmpB protein, which binds to the host cell receptor Ku70, a component of the DNA-dependent protein 
kinase [8]. Cholesterol also acts as a membrane receptor for $R$. prowazekii binding [9-12]. The rOmpA protein is an immunodominant, surface-exposed autotransporter present only in the rickettsial spotted fever group $[12,13]$ and may be involved in the initial adhesion of $R$. rickettsii to the host cell [14]. In the previous study, two putative rickettsial ligands recognized by host cell surface proteins were identified using high resolution 2D-PAGE coupled with mass spectrometry [15]. The results showed that one

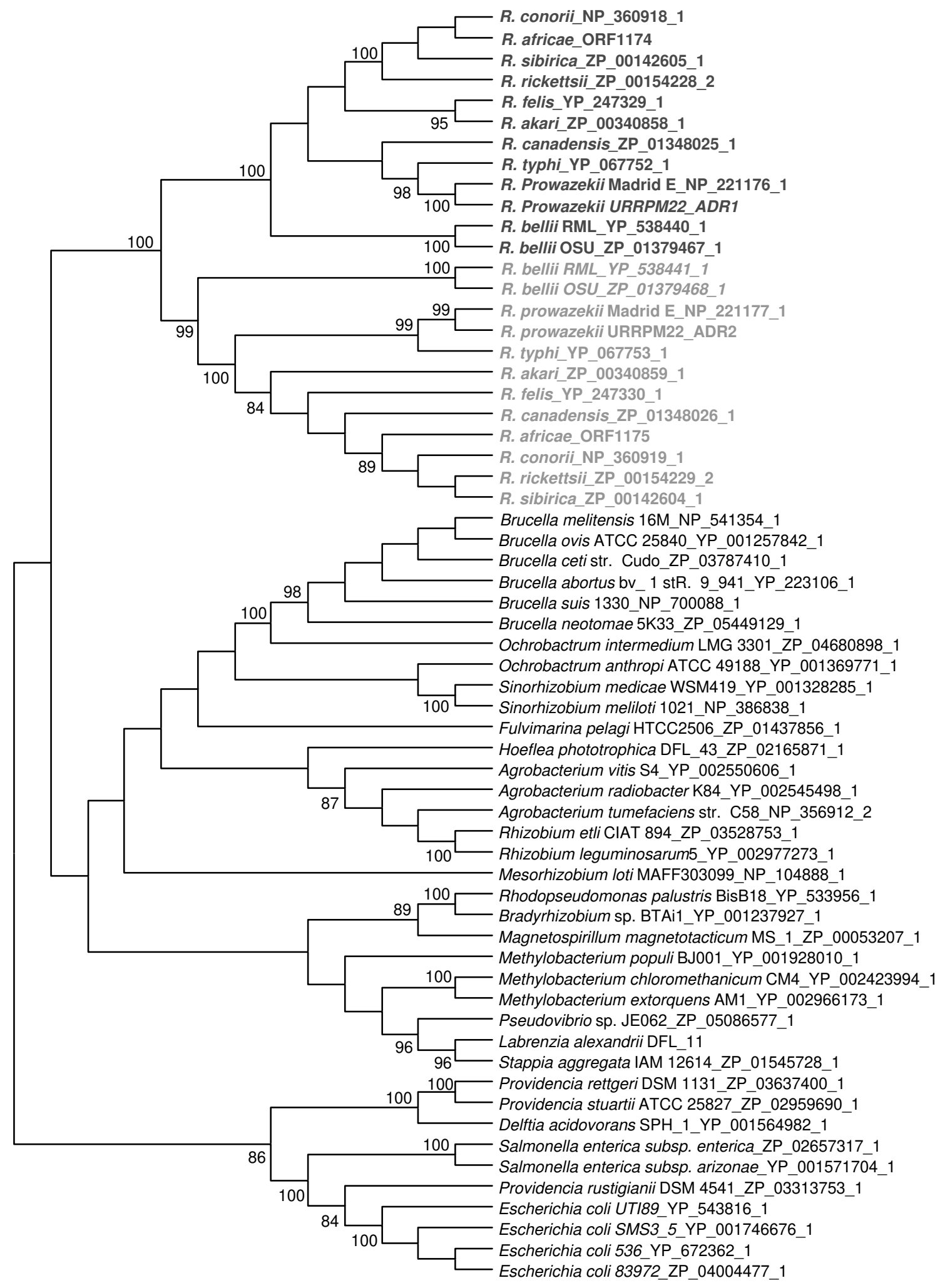

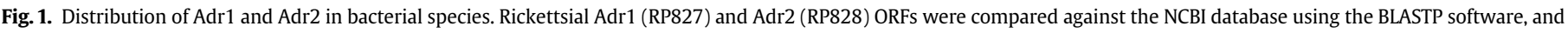
homologs in other bacterial species were identified and it was shown in phylogenetic tree. 
ligand corresponds to the C-terminal extremity of rOmpB called $\beta$-peptide, the second one being a protein of unknown function encoded by RC1281 in R. conorii. RC1281 is located downstream of its paralog, RC1282 [15]. Their orthologous genes in $R$. prowazekii are respectively RP827 and RP828 encoded proteins share striking homologies. They are respectively termed Adr1 and Adr2 for adhesion of Rickettsiae. Because of the presence of a signal peptide in Adr1 and Adr2 and their significant sequence homology with membrane proteins, they likely form a $\beta$ barrel structure within the outer membrane, a location consistent with their putative function as adhesins. Adr1 and Adr2 are ubiquitously present within the Rickettsia genus and may play a critical role in their pathogenicity. However, the precise role of these proteins has not been investigated [15].

First, our attention was to characterize the role of these two adhesins Adr1 and Adr2 in rickettsial entry mechanisms to the host cell. However, we failed expression of recombinant protein Adr1 (RP827) and only the rickettsial gene Adr2 (RP828) could be cloned, expressed and purified in the amounts sufficient for mice immunizations. We produced monoclonal antibody (mAb) anti-Adr2 which was used to determine the neutralizing effect of $R$. prowazekii entry into host cell.

\section{Results}

\subsection{Distribution of Adr1 and Adr2 within bacterial species}

The sequence similarities of the putative adhesins Adr1 and Adr2 for all studied rickettsial species are shown in Suppl. M1. Adr1 and Adr2 are conserved across all rickettsial species, and the highest sequence similarity was found between $R$. sibirica and $R$. africae Adr1 (98\%) and between $R$. sibirica and $R$. rickettsii Adr2 (99\%). The similarity between Adr1 and Adr2 sequences was about $40 \%$ among all rickettsial species. When comparing the rickettsial ORFs (Open Reading Frame) coding for Adr1 and Adr2 against the NCBI database, using the blastP software, we found that these proteins have homologs in other bacterial species (more than $30 \%$ amino acid sequence identity) (Fig. 1). These homologs were found predominantly among the $\alpha$-proteobacteria, but were also identified in $\gamma$-proteobacteria such as Escherichia spp. and Salmonella spp. (Fig. 1).

\subsection{Identification of the rickettsial adhesins using the overlay assay}

To identify proteins expressed on the surface of $R$. prowazekii, an overlay assay was used. As illustrated in Fig. 2, this technique allows for the localization and identification of the rickettsial adhesins. Adr1 (RP827) and Adr2 (RP828) have a theoretical molecular weight of $23 \mathrm{kDa}$ and $26 \mathrm{kDa}$, respectively. To further characterize the adhesins, the separation of the protein was carried out in 2DPAGE and detected by silver staining. Following silver staining (Fig. 2A), intensely stained protein spots were excised from the gel, and matrix-assisted laser desorption ionization time of flight mass spectrometry (MALDI-TOF MS) was used for identification and analysis. A comparison of the 2D-gel/MALDI-TOF MS analysis and the overlay assay demonstrated that the spots identified in both methods were the presumed adhesins in R. prowazekii, RP827 and RP828. Interestingly, we have missed identification of RP827 in $R$. prowazekii and homolog of RP828 in R. conorii [15]. We identified RC1281 which shares sequence homology with RP827 and sca5 ( $\beta$-peptide) respectively in $R$. conorii. Only RP828 and $\beta$-peptide were identified in $R$. prowazekii. Moreover, we identified immunoreactive spot $\mathrm{m} 1$ which corresponds to prohibitin-2 (Mus Musculus), but failed identification of other 2 immunoreactive spots $\mathrm{m} 2$, $\mathrm{m} 3$. Thus, this work completes and confirms previous results [15].

\subsubsection{Cloning, expression and purification of rickettsial adhesins}

Initially, two R. prowazekii genes encoding Adr1 and Adr2 were selected for cloning and expression experiments by using Gateway technology (Invitrogen, Carlsbad, CA, USA). However, despite using 2 different constructions (with $\mathrm{N}$ terminal Histag-DsbC and Histagthioredoxine fusion), we have successfully attempted the expression of only one protein of $R$. prowazekii. Thus, Adr2 was purified in soluble form in sufficient yield by a Nickel affinity chromatography (Suppl. M2) for further experiments. In the case of two different Adr1constructions the cloning was successful, but expression of

A

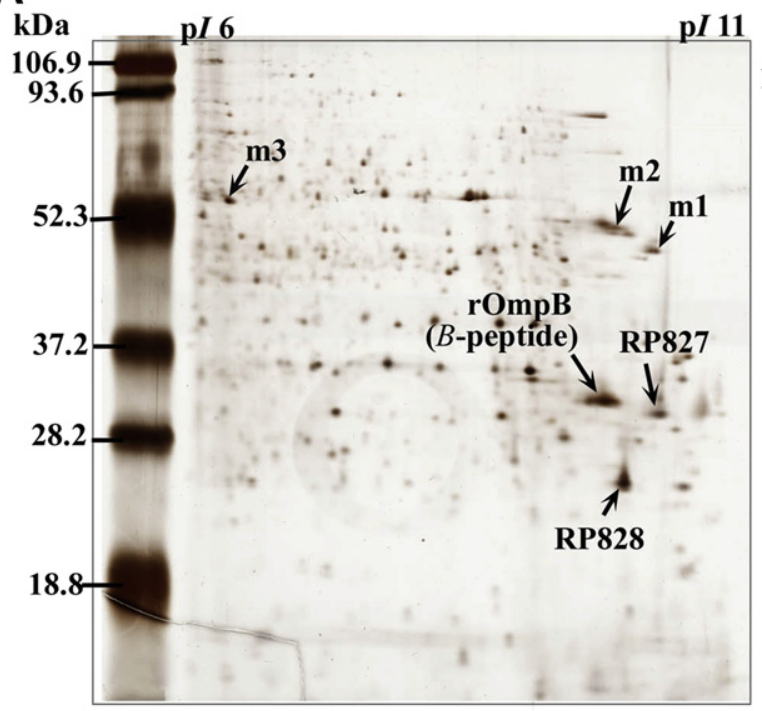

B

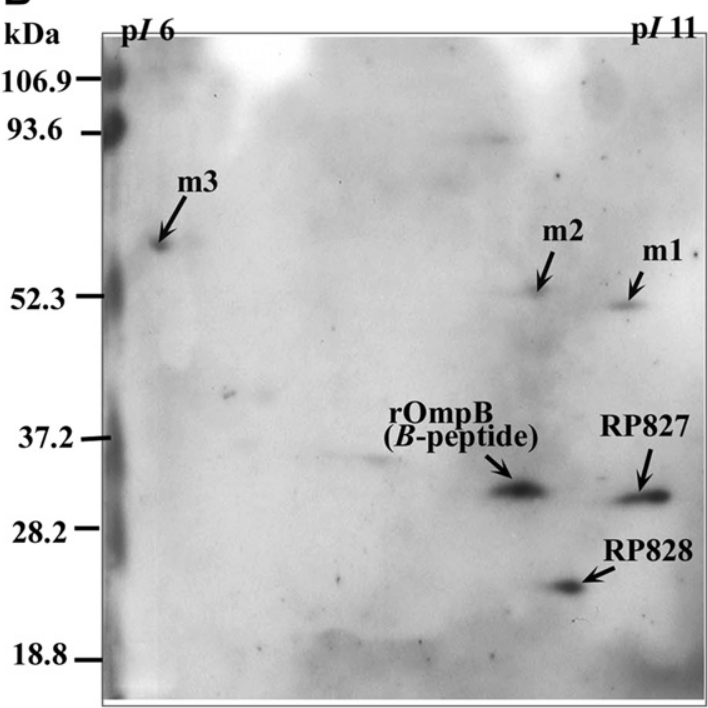

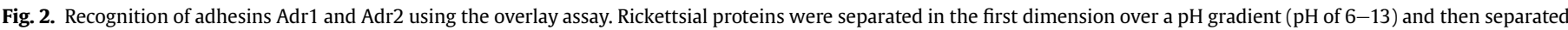

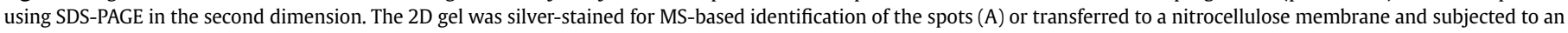
overlay assay (B). 


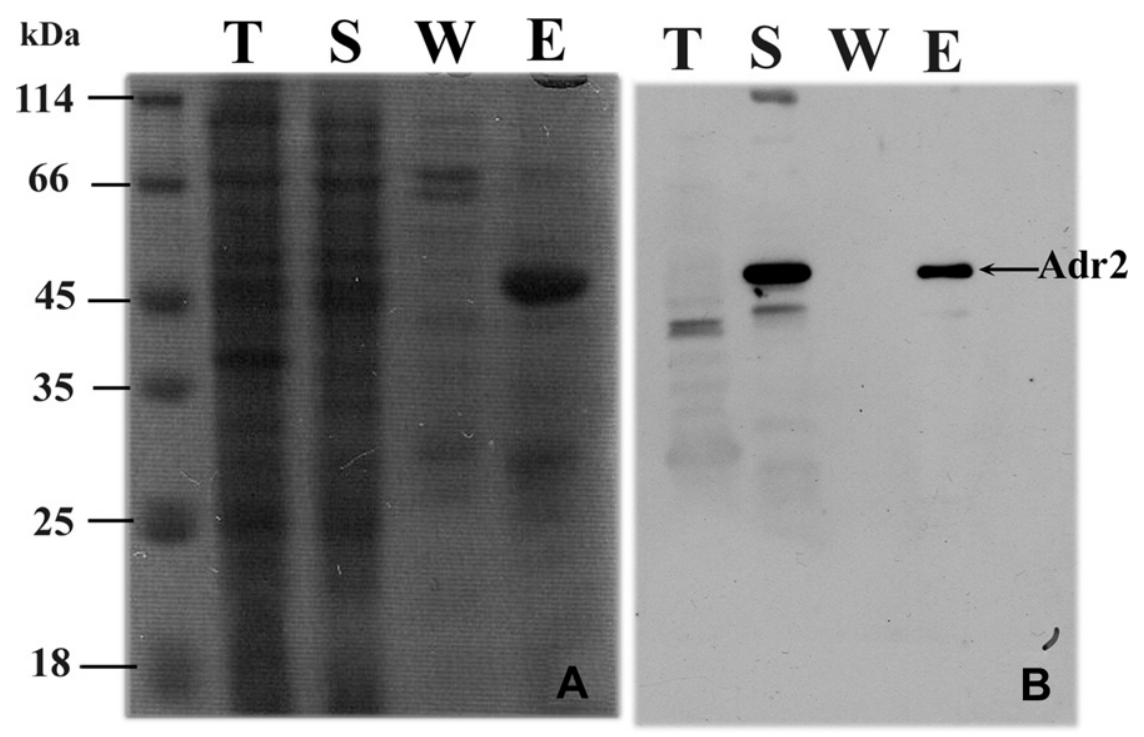

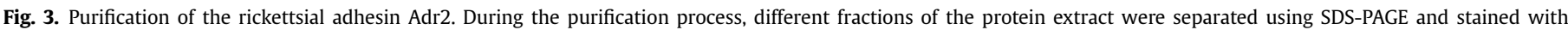
Coomassie blue (A). The identity of purified protein was confirmed using western blot with an anti-his antibody $(\mathrm{B}) . \mathrm{T}=\mathrm{Total}, \mathrm{S}=\mathrm{Soluble}, \mathrm{W}=\mathrm{Wash}, \mathrm{E}=\mathrm{Elution}$.

recombinant fusion proteins (Dsbc-Adr1, trx-Adr1 and trx-Adr2) in Escherichia coli Rosetta (DE3) pLysS strain failed. The migration profile of the recombinant fusion protein is shown in Fig. $3 \mathrm{~A}$ (Coomassie staining) showing DsbC-Adr2 fusion protein about $55 \mathrm{kDa}$, which corresponds to $26 \mathrm{kDa}$ Adr2 protein in fusion with DsbC (28.4 kDa). The identity of recombinant protein Adr2 was confirmed by western blot using an anti-His antibody (Fig. 3B) and by MALDI-TOF MS, respectively.

The genes encoding: groEL and RP059 were subsequently cloned according to manufacturer's instructions (Gateway Cloning Technology/Invitrogen Life Technologies). Then, expression of clones containing an $\mathrm{N}$-His6 tag plus a fusion protein thioredoxin (TRX) [16] that enhances expression of the fusion partner [17,18] was performed as described below. The identity of these proteins was checked by MALDI-TOF as described for Adr2. Purified recombinant proteins were used to generate mAbs included as controls in neutralization assay (see 4).

\subsection{Production of monoclonal antibodies against Adr2}

Monoclonal antibodies (mAbs) were generated against the recombinant $R$. prowazekii Adr2. The antigenic profile of the recombinant protein was analyzed using western blots and silver staining. In a western blot, the monoclonal antibody obtained from immunized mice with $R$. prowazekii Adr2, recognized proteins at the positions corresponding to the theoretical location of Adr2 (Fig. 4A). The corresponding silver-stained spot was identified by MALDI-TOF MS (Fig. 4B) as Adr2 protein.

\subsection{Inhibition of R. prowazekii-induced cytotoxicity with anti-Adr2 monoclonal antibody}

When $R$. prowazekii was pretreated for 20 min with increasing titers of anti-Adr2 monoclonal antibody and then added to L929 cells, cell cytotoxicity measured after $1 \mathrm{~h}$ of incubation was $37 \%$

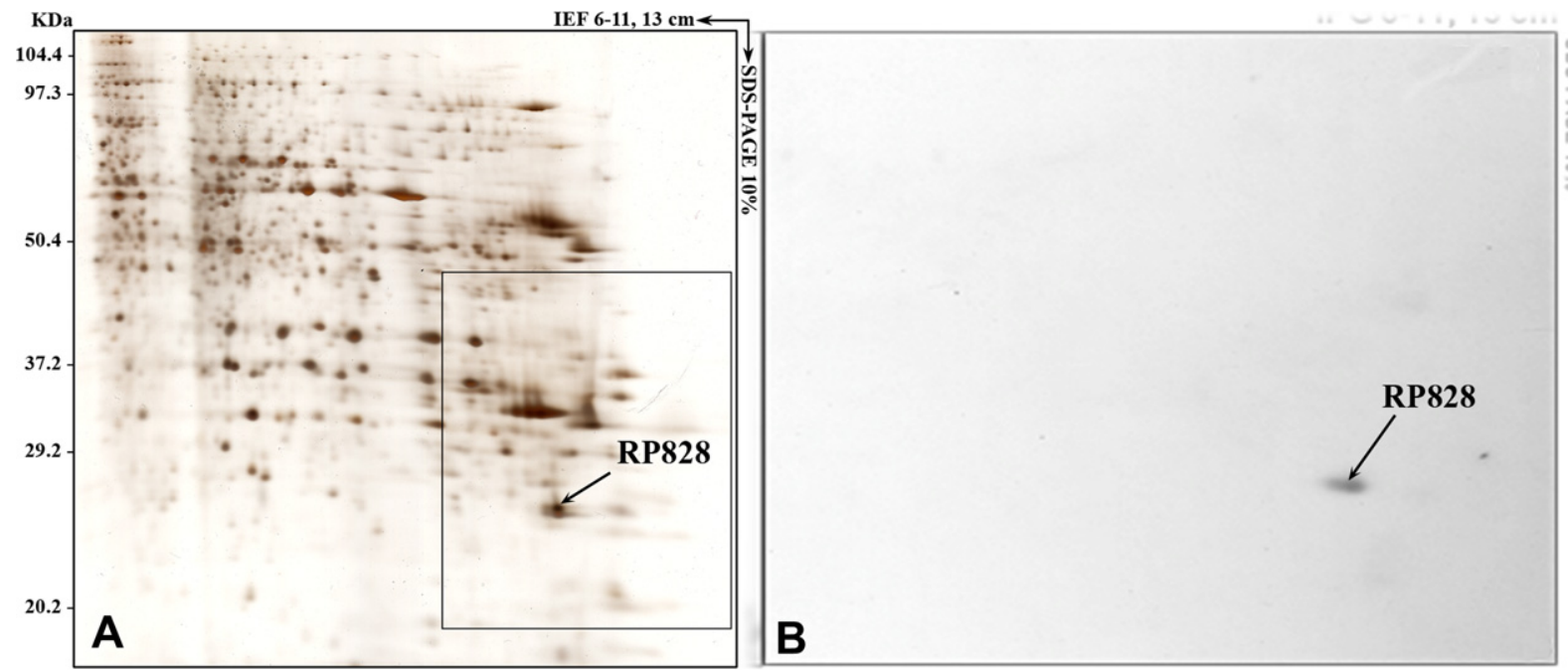

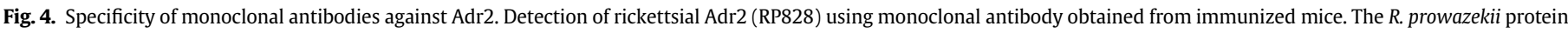
sample was separated using 2D-electrophoresis and visualized using silver staining (B) or western blot with anti-Adr2 (RP828) monoclonal antibody (A). 


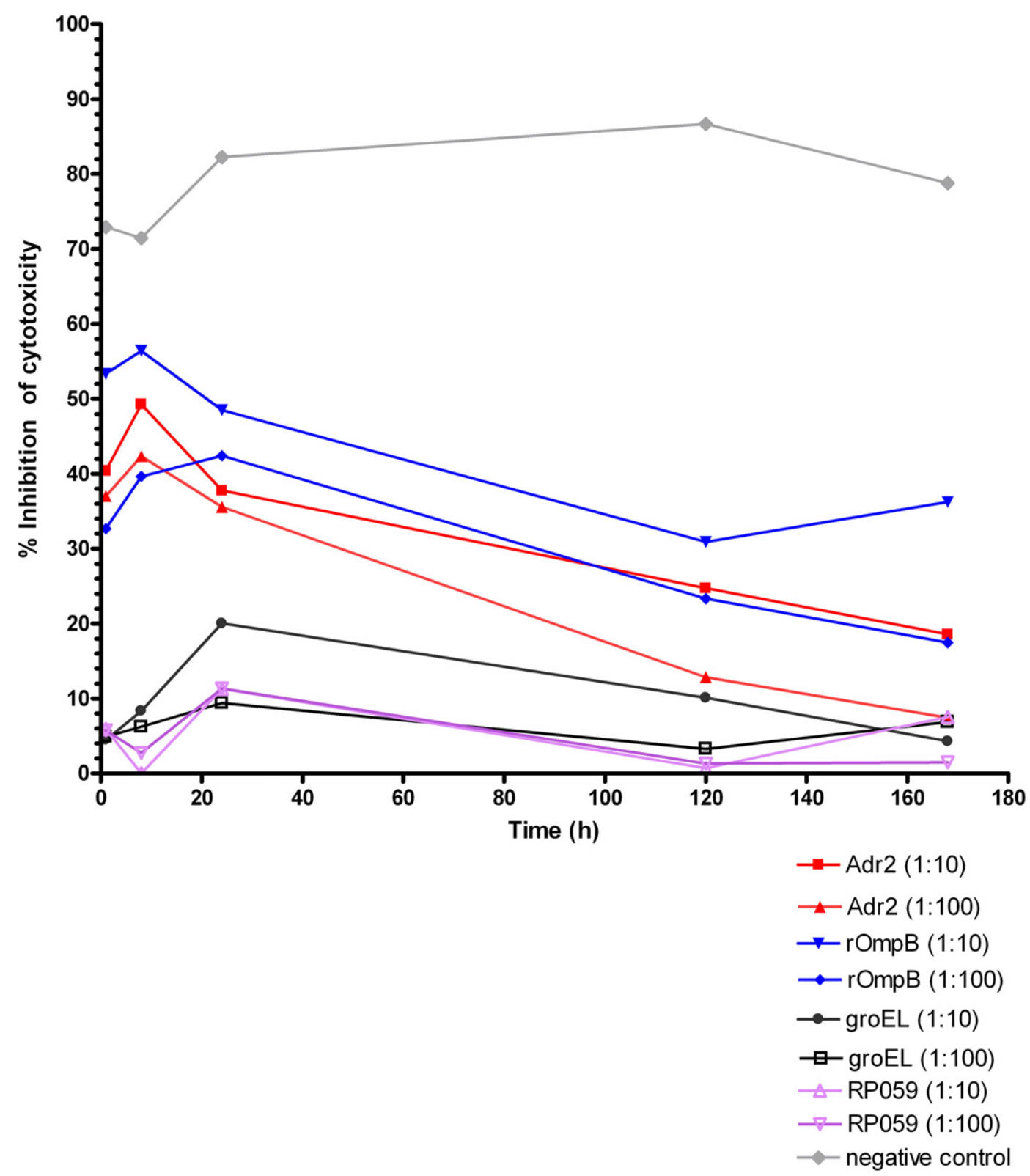

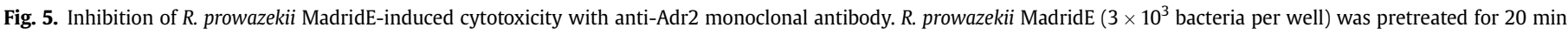

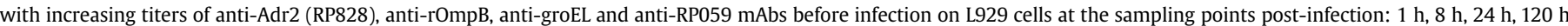

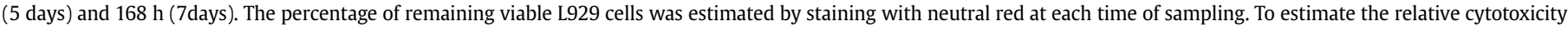

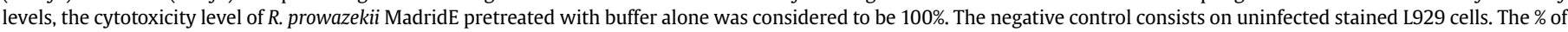
inhibition of rickettsial cytotoxicity was calculated for each $\mathrm{mAb}$.

(dilution 1:100) and 40\% (dilution 1:10), respectively. At the same time of sampling, inhibition of rickettsial entry assessed by rOmpB mAb was $53 \%$ (dilution $1: 10$ ) and $33 \%$ (dilution $1: 100$ ), respectively (Fig. 5). The \% of inhibition assessed by negative specificity controls was about 5\% for both mAbs: groEL and RP059. However, the greatest value of inhibition was obtained for $8 \mathrm{~h}$ sample with the $\%$ of inhibition for Adr2 about 50\% (dilution 1:10) and 43\% (dilution $1: 100$ ). Indeed, the values obtained for rOmpB were $57 \%$ (dilution $1: 10$ ) and $43 \%$ (dilution 1:100). This inhibition was antibody concentration dependent for both Adr2 and rOmpB at $8 \mathrm{~h}$ of incubation. Indeed, the $\%$ of inhibition was less than $10 \%$ for both controls: GroEL and RP059. We observe decreased \% of inhibition for both rOmpB and Adr2 at the time of sampling $24 \mathrm{~h}, 120 \mathrm{~h}$ and $168 \mathrm{~h}$ and ranging from $38 \%$ to $18 \%$ (Adr2, dilution 1:10), from $36 \%$ to $8 \%$ (Adr2, dilution $1: 100$ ) and $48 \%-36 \%$ (rOmpB, dilution $1: 10$ ), 42\%-17\% (rOmpB, dilution 1:100), respectively. No significant variation was observed for GroEL and RP059, except at $24 \mathrm{~h}$ time of sampling, the inhibition was $20 \%$ for groEL. The negative control consists on uninfected cells incubated with buffer only and showed noisy background of non-specific cytotoxicity which ranged about $30 \%$. In addition, Adr2 is sufficient to mediate $R$. prowazekii entry into the cell at early stage of mammalian cell infection. 


\section{Discussion}

In the present study, first, we selected in $R$. prowazekii genome the genes encoding for Adr1(RP827) and Adr2 (RP828) based on previous work [15], sequenced and constructed the phylogenical tree showing the distribution of putative Adr1 and Adr2 within bacterial species including Rickettsiae, $\alpha$ - and $\gamma$-proteobacteria. Secondly, we identified in $R$. prowazekii proteome adhesins Adr 1 and Adr 2 and showed inhibition of $R$. prowazekii entry into the host cells by using monoclonal antibodies generated by mice immunization with recombinant fusion protein Adr2-Dsbc, rOmpB [19], as well as with recombinant proteins TRX-GroEL (RP626) and TRX-spo0J (RP059), respectively. All examined Rickettsia spp. share these both adhesins (Suppl. M1). Previous studies reported other adhesins differentially expressed in Rickettsia like the surface cell antigen (sca) family proteins and the outer membrane proteins, rOmpA and rOmpB $[14,20]$. These genes have been used to study the phylogenetic relationships between Rickettsia spp. The Adr1 and Adr2 gene sequences show some heterogeneity between Rickettsia spp., in accordance with the four distinct rickettsial groups (e.g., the spotted fever group, the typhus group, $R$. canadensis and $R$. bellii). A highly resolved phylogenetic tree at the group level was constructed using the RP828 sequences (Fig. 1). We used overlay assays along with a proteomic approach to identify the adhesins [21]. From a crude extract, proteins were separated using 2D-PAGE with 6-11 strips (Fig. 2), which allowed for better resolution of the protein than the previously optimized conditions [15]. This approach allows for the localization and identification of the rickettsial adhesins using MALDI-TOF MS. Both RP827 and RP828 were detected. We observed the same pattern of results using the overlay assay, as seen in Fig. 2 . Therefore, the protein identification was confirmed using both an overlay assay and western blot.
The expression and purification of recombinant Adr2 (RP828) was performed as previously described [18]. Rickettsiae are obligate intracellular growth requirement of the bacteria poses a challenging obstacle to their genetic manipulation $[22,23]$. Numerous expression vectors are available, and the choice of a vector depends upon the protein to be expressed [22]. We have tested two different constructions in our study: protein in fusion with DsbC and Trx, respectively. Only this DsbC -RP828 could be expressed in vivo. We have also chosen an improved $E$. coli strain for codon usage (Rosetta pLysS). Rare codons are not only strongly associated with low yield of protein expression due to ribosome stalling and abortive translation [24,25], but also implicated in frameshift and amino acid misincorporation [26]. Despite all these efforts to overcome technical limitations, from both selected initially adhesins (RP827 and RP828), we have successfully attempted the expression of only RP828 in fusion with DsbC. The purification of a soluble RP828 in large amounts required for mice immunization, has also revealed a difficult task, but finally achieved by using nickel affinity chromatography.

BLAST and phylogenetic analyses demonstrated that RP827 and RP828 have homologs in other bacteria from different phyla. Some of these bacteria, such as Brucella spp. and Salmonella spp., are intracellular pathogens that bind to and enter the host cell. Adhesins have been shown to play a major role in the early steps of infection: they target a host cell receptor, allowing the bacteria to colonize or become internalized in the host cell. Thus, adhesins are mainly involved in interactions with the host cell to promote entry [27]. However, the inhibition of rickettsiae-induced cytotoxicity with monoclonal anti-Adr2 antibody has showed a greatest impact on bacterial cell entry at $8 \mathrm{~h}$ post-infection (around 50\% of inhibition) and then decreased progressively to attempt $18 \%$ of inhibition at day 7. These, correlated to the inhibition of rickettsiae-induced

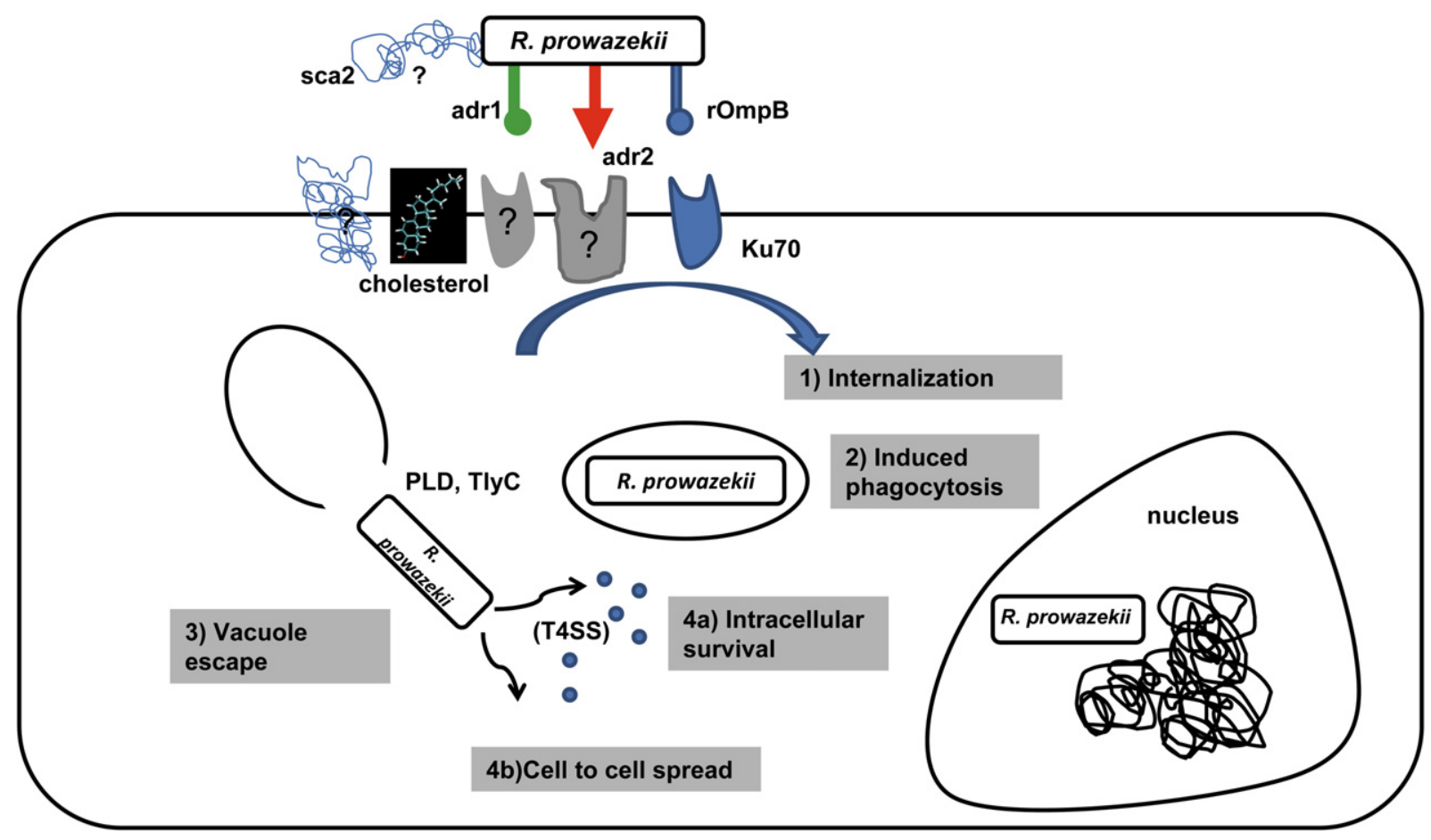

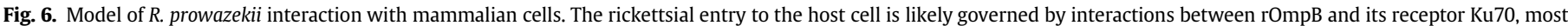

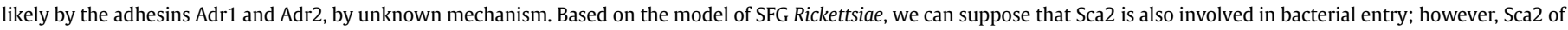

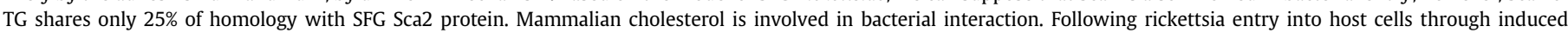

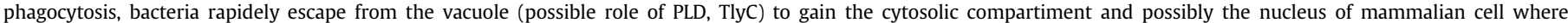

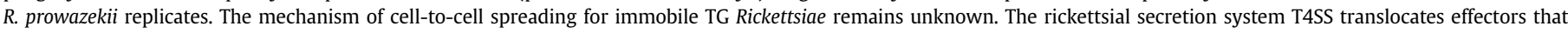
should contribute to the intracellular survival of $R$. prowazekii. 
cytotoxicity with monoclonal anti-rOmpB antibody. Thus, Adr2 is sufficient to mediate $R$. prowazekii entry into the cell at early stage of mammalian cell infection. However, the method used in this work allowed only global appreciation of this phenomenon and remains the focus on more detailed mechanisms of further studies. Thus, this result is expected if we consider rOmpA, rOmpB and RP827 are also involved in entry mechanisms of Rickettsiae into the host cell. Thus far, $\mathrm{rOmpA}(\mathrm{sca} 0)$ and $\mathrm{rOmpB}$ (sca5), have been shown to participate in adhesion of Rickettsiae to mammalian cells in vitro $[8,14,20,28]$ Recently, Cardwell et al., [29] shown that Sca2 protein is sufficient to mediate adherence to and invasion of $R$. conorii infected cultured mammalian epithelial and endothelial cells. Inhibition (ca 30\%) of these phenotypes with purified soluble Sca2 protein confirms that invasion of host cells is specifically mediated by Sca2 [29]. However, the \% of protein sequence identity is about $25 \%$ for $R$. typhi, which is like $R$. prowazekii belongs to Typhus group (TG) [29]. Its role within TG remains to be elucidated. The ability of $R$. prowazekii to induce internalization into mammalian cells is likely governed by numbered adhesin-receptor interactions which involved several partners as RP827, RP828, rOmpB proteins, Sca2 protein (Fig. 6). Indeed, the identification of mammalian receptors involved in adhesins-mediated uptake of mammalian cells is should be undertaken in ongoing studies.

Monoclonal antibodies against adhesins are an excellent tool to study these interactions between rickettsial adhesins and host mammalian receptors, may also be an efficient therapeutic agent to block binding to target cells and inhibit bacterial entry into the host cell. NadA-specific antibodies have been effective in the control of $N$. meningitidis [30]. Rickettsial surface proteins have been used to produce monoclonal antibodies that conferred protective immunity in guinea pigs and mice [14]. In addition, prophylactic vaccination with adhesins can prevent bacterial infection [31]. Despite that the monoclonal antibodies against RP828 produced in this study have not inhibited efficiently the adhesion/entry of Rickettsia to the host cell; however, the further orientations should focus on infectivity neutralization assays in vivo. Monoclonal antibodies may also be used to elucidate the Rickettsial physiological and pathological mechanisms. In Orientia tsutsugamushi, a monoclonal antibody was used to characterize its life cycle in endothelial cells [30]. Adr1 and Adr2 may act as broad-spectrum vaccine targets for all Rickettsia spp. since they are well conserved in the Rickettsia spp. examined.

\section{Conclusion}

Adhesion and invasion are the crucial stages of obligate intracellular infection of host cells, and adhesins are critical in bacterial virulence. We showed that Adr2 is probably one of several factors involved in adhesion/entry of $R$. prowazekii into host cell. Further investigations involving Adr2 and other adhesins may lead to the development of antimicrobials to prevent the emergence and recurrence of infections.

\section{Materials and methods}

\subsection{Propagation of $R$. prowazekii and DNA purification}

R. prowazekii (URRPM22) was propagated at $32{ }^{\circ} \mathrm{C}$ in monolayers of murine fibroblast L929 cell (ATCC CCL 1, European Collection of Cell Cultures 85011425) in Eagle's minimum essential medium (MEM, Invitrogen, Paisley, UK) supplemented with $2 \%$ fetal bovine serum (FCS, Gibco) and 2\% L-glutamine (Gibco). Total genomic DNA was extracted from infected cells using the QIAamp DNA Mini Kit (Qiagen, Hilden, Germany).

\subsection{Cloning}

The $R$. prowazekii RP827 , RP828, groEl, RP059 genes were amplified using primers designed for Gateway cloning (Table 1) and the Expand High Fidelity PCR System (Roche Diagnostics, Maylan, France). Genes were amplified with 30 cycles of denaturation for $30 \mathrm{~s}$ at $94{ }^{\circ} \mathrm{C}$, annealing for $45 \mathrm{~s}$ at $50{ }^{\circ} \mathrm{C}$ and elongation for $2 \mathrm{~min}$ at $68{ }^{\circ} \mathrm{C}$, followed by termination for $5 \mathrm{~min}$ at $68{ }^{\circ} \mathrm{C}$ in a PE 9600 thermal cycler (Applied bio systems, Courtaboeuf, France). The resulting PCR products were purified through PEG precipitation and inserted into the pDONR201 vector (Gateway Cloning System, Invitrogen, USA) by the BP recombination reaction, and according to the manufacturer's instructions. The products of the recombination reactions were transformed into competent DH5 $\alpha$ cells and selected on LB-agar plates containing kanamycin $(50 \mu \mathrm{g} / \mathrm{ml})$. Clones were confirmed using sequencing and the dRhodamine Terminator Cycle Sequencing Ready Reaction Kit (Applied bio systems, Foster City, Ca, USA). The second step of Gateway cloning was gene transfer into a destination vector (pDest17) by the LR reaction (Gateway Cloning System, Invitrogen, Carlsbad, CA, USA). The resulting expression plasmids were transformed into competent DH5 $\alpha$ cells, selected on LB-agar plates with ampicillin $(50 \mu \mathrm{g} / \mathrm{ml})$ and confirmed by PCR.

\subsection{Expression and purification}

The expression and purification of recombinant proteins were performed as previously described $[18,32]$. Briefly, the plasmids

Table 1

List of primers. Primers designed for Gateway cloning to amplify the target genes.

\begin{tabular}{|c|c|c|c|}
\hline Gene & Protein & Strain & Primers used \\
\hline RP827 & DsbC - Adr1 & MadridE/RP22 & $\begin{array}{l}\text { F:5'-GGGG ACA AGT TTG TAC AAA AAA GCA GGC Ttcgatcatgatatgaattgttctgtag }-3^{\prime} \\
\text { R:5'-GGGG AC CAC TTT GTA CAA GAA AGC TGG GTC CTA catatcaaatcttaatcctgccattaag- } 3^{\prime}\end{array}$ \\
\hline RP828 & DsbC-Adr2 & MadridE/RP22 & $\begin{array}{l}\text { F:5'-GGGG ACA AGT TTG TAC AAA AAA GCA GGC Ttcgagtgcattgataatgaatgg- } 3^{\prime} \\
\text { R:5'-GGGG AC CAC TTT GTA CAA GAA AGC TGG GTC CTAtataccaatcttacacctactgtc }-3^{\prime}\end{array}$ \\
\hline RP827 & TRX-Adr1 & MadridE/RP22 & $\begin{array}{l}\text { F:5'GGGGACAAGTTTGTACAAAAAAGCAGGCTTAGAAAACCTGTACTTCCAGGGT-GATCATGATAT } \\
\text { GAATTGTTCTGTAGATTCA-3' } \\
\text { R:5'- GGGGACCACTTTGTACAAGAAAGCTGGGTCttatta- CATATCAAATCTTAATCCTGCC-3' }\end{array}$ \\
\hline RP828 & TRX-Adr2 & MadridE/RP22 & $\begin{array}{l}\text { F:5'GGGGACAAGTTTGTACAAAAAAGCAGGCTTAGAAAACCTGTACTTCCAGGGT-GAGTGCATTGA } \\
\text { TAATGAATGG-3' } \\
\text { R:5' - GGGGACCACTTTGTACAAGAAAGCTGGGTCttatta-TATACCAAATCTTACACCTACTGTC-3' }\end{array}$ \\
\hline $\begin{array}{l}60 \text { KD CHAPERONIN } \\
\text { (groEL) RP626 }\end{array}$ & TRX-groEL & MadridE & $\begin{array}{l}\text { F:5'-GGGGACAAGTTTGTACAAAAAAGCAGGCTTAGAAAACCTGTACTTCCAGGGT-ACAACGAAACTT } \\
\text { ATTAAACACG-3' } \\
\text { R:5'-GGGGACCACTTTGTACAAGAAAGCTGGGTCttatta-GAAGTCCATACCACCCATGCCAC-3' }\end{array}$ \\
\hline $\begin{array}{l}\text { Stage } 0 \text { sporulation } \\
\text { protein } \mathrm{J} \text { (spo0J) RP059 }\end{array}$ & TRX-spo0J & MadridE & $\begin{array}{l}\text { F:5'-GGGGACAAGTTTGTACAAAAAAGCAGGCTTAGAAAACCTGTACTTCCAGGGT-GTGAAAAATAAA } \\
\text { GGGCTAGGGC-3 } \\
\text { R:5'-GGGGACCACTTTGTACAAGAAAGCTGGGTCttatta- ATTTAATTTTGATAATATTAAAT-3' }\end{array}$ \\
\hline
\end{tabular}

ATTB sequences are shown in bold. The Tev site is shown as underlined. The preferred STOP codon is (tta). It is doubled, as shown in miniscules for Trx-adhesins. 
encoding Adr1 or Adr2, as well as groEL and RP_059 were used to transform E. coli strain Rosetta (DE3) pLysS (Novagen, Madison, WI, USA). For expression of the recombinant proteins, bacteria were grown in the auto-induction medium ZYP5052 $(1.4 \mathrm{~L})$ at $37^{\circ} \mathrm{C}$ for $4 \mathrm{~h}$ at $200 \mathrm{rpm}$ [33]. Following this incubation, the temperature was lowered to $17{ }^{\circ} \mathrm{C}$, and the cells were pelleted after $18 \mathrm{~h}$. The bacterial pellet was resuspended in lysis buffer $(50 \mathrm{mM}$ Tris, $300 \mathrm{mM} \mathrm{NaCl}, 10 \mathrm{mM}$ imidazole $\mathrm{pH}$ 8.0, $0.25 \mathrm{mg} / \mathrm{ml}$ lysozyme and $1 \mathrm{mM}$ PMSF) and frozen at $-80^{\circ} \mathrm{C}$ for at least $1 \mathrm{~h}$. After thawing the bacterial pellets and adding DNAse I $(2 \mu \mathrm{g} / \mathrm{ml})$ and $\mathrm{MgSO} 4(20 \mathrm{mM})$, the lysed cells were centrifuged to separate the soluble fraction from the bacterial debris. The protein was purified using a nickel affinity column. For this purpose, the supernatant containing the recombinant protein DsbC-Adr2 was loaded on a 5-ml HisTrap crude nickel column (GE Healthcare, Chalfont St. Giles, UK) equilibrated in buffer A (50 mM Tris $\mathrm{pH} 8.0,300 \mathrm{mM} \mathrm{NaCl}$ and $10 \mathrm{mM}$ imidazole) (Suppl. M2). The column was then washed with five volumes of buffer B (buffer A with $500 \mathrm{mM}$ imidazole) to remove endogenous nickel-binding proteins. The protein was eluted with buffer C (buffer A $+250 \mathrm{mM}$ imidazole). The protein-containing fractions were pooled and stored in $50 \%$ glycerol at $-20{ }^{\circ} \mathrm{C}$. The identity of the isolated protein was confirmed using mass spectrometry.

\subsection{Production of mAbs against Adr2 (RP828), rOmpB, groEL and stage sporulation protein (RP059)}

The monoclonal antibody (MAb) raised against rOmpB was produced as previously described [19]. The remaining MAbs were produced by inoculation of 6- to 8-week-old immunocompetent BALB/c mice (Charles River Laboratories, St. Aubin Les Elbeuf, France) with a total of $25 \mu \mathrm{g}$ of purified recombinant proteins Adr2, groEL, RP059 respectively, with CpG adjuvant, respectively, as described previously [34] [35]. Three days after the last injection, the mice were euthanized, and the spleen was removed aseptically. Splenocytes were isolated and prepared for fusion with mouse myeloma cell line NS-1, as described [34]. Hybridoma clones were selected in RPMI medium (Invitrogen, Carlsbad, CA, USA) containing 15\% FCS supplemented with HAT medium (Invitrogen, Carlsbad, CA, USA). Colonies were screened using an ELISA after 10 days. The isotypes of the MAbs were determined with an ImmunoType Mouse Monoclonal Antibody Isotyping kit with antisera to mouse immunoglobulin M (IgM), IgA, IgG1, IgG2a, IgG2b, and IgG3 (Sigma Chemical Co.). The antiserum was affinity- purified by use of MAbTrap $^{\text {TM }}$ Kit (GE Healthcare) according to the manufacturer's instructions. Serum levels of recombinant protein-specific IgG was determined by ELISA, as previously described [35]. The higher dilution of each affinity- purified antibody recognizing the recombinant protein was estimated. In parallel, the protein content in eluted fraction was estimated by modified Bradford method (Biorad), as previously described [35]. The protein concentration in elution fraction was: $11.96 \mu \mathrm{g} / \mathrm{ml}$ (Adr2), $8.39 \mu \mathrm{g} / \mathrm{ml}$ (rOmpB), $8.23 \mu \mathrm{g} / \mathrm{ml}$ (GroEL), $9.37 \mu \mathrm{g} / \mu \mathrm{l}$ (RP059) respectively. The specificity of mAbs raised against groEl and RP059 was assessed by immunoblotting (Suppl. M3).

\subsubsection{ELISA}

ELISAs was performed as previously described [36] with minor modifications. Microtiter plates were coated separately with $40 \mu \mathrm{g}$ of each recombinant protein from this study in $100 \mu \mathrm{l}$ of carbonate buffer overnight at $4{ }^{\circ} \mathrm{C}$. The coated wells were washed with phosphate buffered saline (PBS) containing 0.05\% Tween 20 and blocked with $100 \mu \mathrm{l}$ of $3 \%$ non-fat milk in PBS for $1 \mathrm{~h}$ at room temperature (RT). Hybridoma supernatant $(50 \mu \mathrm{l})$ was then added as a primary antibody, and the plates were incubated for $1 \mathrm{~h}$ at RT before washing with PBS supplemented with 0.1\% Tween 20 . Following the washes, $100 \mu \mathrm{l}$ of goat anti-mouse biotin was added, and the plates were incubated for $1 \mathrm{~h}$ at RT washed with $0.1 \%$ Tween 20 in PBS. The plates were then incubated with streptavidin for $1 \mathrm{~h}$ and washed with $0.1 \%$ Tween 20 in PBS. Following this wash, $100 \mu \mathrm{l}$ of ortho-phenylenediamine (OPD) was added, and the plates were incubated for $2-3 \mathrm{~min}$ at RT. After $10 \mathrm{~min}$ of incubation with OPD at room temperature, the reaction was stopped with $100 \mathrm{ml} /$ well $\mathrm{NaOH} 1 \mathrm{M}$. Color development was assessed with a microplate reader (Multiskan EX, Labsystems, Thermo Fisher Scientific, Waltham, MA) at a wavelength of $490 \mathrm{~nm}$. Any samples exhibiting absorbance above or similar to the positive control was considered as positive. A positive control consisted in polyclonal positive serum of $R$. prowazekii and a negative control consisted in preimmune negative serum.

\subsection{Sample preparation for 2D-electrophoresis}

R. prowazekii RP22 was propagated in a confluent monolayer of murine fibroblast L929 cell line and purified on a renografin gradient as previously reported [37]. Purified bacteria were lysed by sonication in a solubilizing buffer ( $7 \mathrm{M}$ urea, $2 \mathrm{M}$ thiourea, $30 \mathrm{mM}$ Tris, $4 \% \mathrm{w} / \mathrm{v}$ CHAPS) and centrifuged $\left(10,000 \mathrm{~g}, 20 \mathrm{~min}, 4{ }^{\circ} \mathrm{C}\right)$ to remove cell debris and unbroken cells. Soluble proteins were precipitated using the PlusOne 2-D Clean-Up Kit (GE Healthcare, Chalfont St. Giles, UK). The final pellet was resuspended in solubilizing buffer, and the protein concentration was determined using the Bio-Rad DC Protein Assay.

\subsubsection{D-electrophoresis and silver staining}

Immobiline DryStrips gels $(13 \mathrm{~cm}$, pH 6-11, GE Healthcare, Chalfont St. Giles, UK) were rehydrated overnight in $250 \mu$ l rehydration buffer ( $7 \mathrm{M}$ urea, $4 \% \mathrm{w} / \mathrm{v}$ CHAPS, $12 \mu \mathrm{l} / \mathrm{ml}$ DeStreak, $0.5 \% \mathrm{v} / \mathrm{v}$ immobiline $\mathrm{pH}$ gradient (IPG) buffer (GE Healthcare, Chalfont St. Giles, UK) containing $30 \mu \mathrm{g}$ of solubilized proteins. IEF was carried out according to the manufacturer's protocol (IPGphor II, GE Healthcare, UK). Prior to electrophoresis in the second dimension, the strips were equilibrated for $15 \mathrm{~min}$ in equilibration buffer $(30 \%$ v/v glycerol, $2 \% \mathrm{w} / \mathrm{v}$ SDS, $6 \mathrm{M}$ urea, $50 \mathrm{mM}$ Tris $-\mathrm{HCl}$, bromophenol blue, $\mathrm{pH} 8.8$ ) containing $65 \mathrm{mM}$ DTT. This step was then repeated using equilibration buffer supplemented with $100 \mathrm{mM}$ iodoacetamide. The strips were then embedded in $0.5 \%$ agarose, and the proteins were resolved by electrophoresis through a $10 \%$ SDSpolyacrylamide gel (EttanTM DALT, GE Healthcare, Chalfont St. Giles, UK) at $5 \mathrm{~W} / \mathrm{gel}$ for $30 \mathrm{~min}$, followed by $17 \mathrm{~W} / \mathrm{gel}$ for $4-5 \mathrm{~h}$. Following electrophoresis, the gels were silver-stained, and digital images were generated using transmission scanning (ImageScanner, GE Healthcare, Chalfont St. Giles, UK) to identify the proteins. Spots excised from the gel were identified using MALDITOF MS and a Bruker Ultraflex spectrometer (Bruker Daltonics, Wissembourg, France) as described previously [38].

\subsubsection{Overlay assay}

Overlay assays were performed as previously described [15]. $R$. prowazekii extracts (30 $\mu \mathrm{g}$ ) were separated using 10\% SDS-PAGE. Both silver staining and an overlay assay were then performed. Resolved 2D gels were transferred onto nitrocellulose membranes (Trans-Blot transfer medium, pure nitrocellulose membrane, BioRad, Hercules, CA, USA) for $2 \mathrm{~h}$ using a semi-dry transfer unit (Hoefer TE 77, GE Healthcare, Chalfont St. Giles, UK). Membranes were blocked in PBS supplemented with $0.2 \%$ Tween 20 and $5 \%$ non-fat dried milk (PBS-Tween-Milk) for $1.5 \mathrm{~h}$. After blocking, the membranes were incubated for $1.5 \mathrm{~h}$ at $4{ }^{\circ} \mathrm{C}$ with biotinylated Vero cells $(1: 100)$. The reactive spots were detected using peroxidase- 
labeled streptavidin (1:1000; Becton-Dickinson, San Jose, CA) and chemiluminescence (ECL; GE Healthcare, Chalfont St. Giles, UK).

\subsection{Western blot}

Following the transfer of rickettsial proteins, the nitrocellulose membranes were blocked in PBS-Tween-Milk for $1 \mathrm{~h}$ before incubation with the serum of a mouse immunized with recombinant Adr2 (1:100 dilution in PBS-Tween-Milk). Following a1 h incubation, the membranes were washed three times for $10 \mathrm{~min}$ in $0.2 \%$ PBS-Tween 20 and probed with a 1:1000 dilution of a horseradish peroxidase-conjugated goat anti-mouse secondary antibody (GE Healthcare, Chalfont St. Giles, UK). The blots were washed with $0.2 \%$ Tween 20 in PBS, and chemiluminescence was used to detect protein bands (ECL, GE Healthcare, Chalfont St. Giles, UK). The resulting signal was detected on Hyperfilm ECL (GE Healthcare, Chalfont St. Giles, UK) using an automated film processor (Hyperprocessor, GE Healthcare, Chalfont St. Giles, UK). We used to work with freshly transferred proteins into the nitrocellulose membrane. We have never used twice the same membrane for Western blotting experiments.

\subsection{Inhibition of R. prowazekii-induced cytotoxicity on L929 cells}

L929 cells grown in MEM supplemented with $4 \%$ fetal calf serum and $2 \mathrm{mmol} / \mathrm{L}$ L-glutamine, in microtiter plates, were inoculated with 3000 pfu of $R$. prowazekii/well [35,39]. To examine whether Adr2 monoclonal antibody could inhibit the cytotoxicity of $R$. prowazekii, bacteria purified on sucrose gradient were incubated for $20 \mathrm{~min}$ at $4{ }^{\circ} \mathrm{C}$, with increasing dilutions of antibody, before incubation with L929 cells [35]. After $1 \mathrm{~h}, 8$ h, 24 h, 120 h (5 days) and $168 \mathrm{~h}$ ( 7 days) of incubation at $37{ }^{\circ} \mathrm{C}$ in $5 \% \mathrm{CO} 2$, the cell culture supernatant was removed, and cell monolayer were incubated for $1 \mathrm{~h}$ at $37^{\circ} \mathrm{C}$ with $50 \mu \mathrm{l}$ of neutral red dye (0.15\% in saline [pH 5.5]). The viability of bacteria has been checked by inoculation of cell monolayer with the remaining cell culture supernatant. The same conditions were applied for specificity controls: (i) positive control performed with rOmpB mAb [19], which is known that rOmpB protein is involved in rickettsial entry [12], (ii) negative controls performed with mAbs raised against GroEL and RP059 which are most likely do not involved in cell cytotoxicity. Dye not absorbed by the viable cells was removed by 2 washes with PBS ( $\mathrm{pH}$ 6.5). Finally, the dye absorbed by the cells was extracted by the addition of $100 \mu$ of ethanol in PBS (pH 4.2), and the optical density at $492 \mathrm{~nm}$ was measured with a microplate reader (Multiskan EX, Labsystems, Thermo Fisher Scientific, Waltham, MA). At least three independent assays were performed. The results were expressed as a percentage of cytotoxicity obtained with $R$. prowazekii incubated with the buffer alone. The graphs were compiled with GraphPad Prisme software (version 3.0, GraphPad Software, San Diego, CA, USA.).

\section{Acknowledgments}

The authors would like to thank Bernard Campagna for his help.

\section{Appendix. Supplementary material}

Supplementary data related to this article can be found online at doi:10.1016/j.micpath.2011.01.009.

\section{References}

[1] Winkler HH. Rickettsia species (as organisms). Annu Rev Microbiol 1990;44:131-53.
[2] Birg ML, La SB, Roux V, Brouqui P, Raoult D. Isolation of Rickettsia prowazekii from blood by shell vial cell culture. J Clin Microbiol 1999 Nov; 37(11):3722-4.

[3] Wisseman Jr CL, Waddell AD. In vitro studies on rickettsia-host cell interactions: intracellular growth cycle of virulent and attenuated Rickettsia prowazeki in chicken embryo cells in slide chamber cultures. Infect Immun 1975 Jun;11(6):1391-404

[4] Renesto P, Ogata H, Audic S, Claverie JM, Raoult D. Some lessons from Rickettsia genomics. FEMS Microbiol Rev 2005 Jan;29(1):99-117.

[5] Soto GE, Hultgren SJ. Bacterial adhesins: common themes and variations in architecture and assembly. J Bacteriol 1999 Feb;181(4):1059-71.

[6] Uchiyama T, Kawano H, Kusuhara Y. The major outer membrane protein rOmpB of spotted fever group rickettsiae functions in the rickettsial adherence to and invasion of Vero cells. Microbes Infect 2006 Mar;8(3):801-9.

[7] Blanc G, Ngwamidiba M, Ogata H, Fournier PE, Claverie JM, Raoult D. Molecular evolution of rickettsia surface antigens: evidence of positive selection. Mol Biol Evol 2005 Oct;22(10):2073-83.

[8] Martinez JJ, Seveau S, Veiga E, Matsuyama S, Cossart P. Ku70, a component of DNA-dependent protein kinase, is a mammalian receptor for Rickettsia conorii. Cell 2005 Dec 16;123(6):1013-23.

[9] Walker DH, Ismail N. Emerging and re-emerging rickettsioses: endothelial cell infection and early disease events. Nat Rev Microbiol 2008 May; 6(5):375-86.

[10] Valbuena G, Walker DH. Infection of the endothelium by members of the order Rickettsiales. Thromb Haemost 2009 Dec;102(6):1071-9.

[11] Choong IC, Serafimova I, Fan J, Stockett D, Chan E, Cheeti S, et al. A diaminocyclohexyl analog of SNS-032 with improved permeability and bioavailability properties. Bioorg Med Chem Lett 2008 Nov 1;18(21):5763-5.

[12] Balraj P, Renesto P, Raoult D. Advances in rickettsia pathogenicity. Ann N Y Acad Sci 2009 May;1166:94-105.

[13] Walker DH. Rickettsiae and rickettsial infections: the current state of knowledge. Clin Infect Dis 2007 Jul 15;45(Suppl. 1):S39-44.

[14] Li H, Walker DH. rOmpA is a critical protein for the adhesion of Rickettsia rickettsii to host cells. Microb Pathog 1998 May;24(5):289-98.

[15] Renesto P, Samson L, Ogata H, Azza S, Fourquet P, Gorvel JP, et al. Identification of two putative rickettsial adhesins by proteomic analysis. Res Microbiol 2006 Sep;157(7):605-12.

[16] Canaan S, Maurin D, Chahinian H, Pouilly B, Durousseau C, Frassinetti F, et al. Expression and characterization of the protein Rv1399c from Mycobacterium tuberculosis. A novel carboxyl esterase structurally related to the HSL family. Eur J Biochem 2004 Oct;271(19):3953-61.

[17] Vincentelli R, Bignon C, Gruez A, Canaan S, Sulzenbacher G, Tegoni M, et al. Medium-scale structural genomics: strategies for protein expression and crystallization. Acc Chem Res 2003 Mar;36(3):165-72.

[18] Vincentelli R, Canaan S, Offant J, Cambillau C, Bignon C. Automated expression and solubility screening of His-tagged proteins in 96-well format. Anal Biochem 2005 Nov 1;346(1):77-84

[19] Xu W, Raoult D. Distribution of immunogenic epitopes on the two major immunodominant proteins (rOmpA and rOmpB) of Rickettsia conorii among the other rickettsiae of the spotted fever group. Clin Diagn Lab Immunol 1997 Nov;4(6):753-63.

[20] Uchiyama T. Adherence to and invasion of Vero cells by recombinant Escherichia coli expressing the outer membrane protein rOmpB of Rickettsia japonica. Ann N Y Acad Sci 2003 Jun;990:585-90.

[21] Girard V, Mourez M. Adhesion mediated by autotransporters of Gram-negative bacteria: structural and functional features. Res Microbiol 2006 Jun;157 (5):407-16.

[22] Renesto P, Raoult D. From genes to proteins: in vitro expression of rickettsial proteins. Ann N Y Acad Sci 2003 Jun;990:642-52.

[23] Kuzyk MA, Thorton JC, Kay WW. Antigenic characterization of the salmonid pathogen Piscirickettsia salmonis. Infect Immun 1996 Dec;64 (12):5205-10.

[24] Kerrigan JR, Crandall JR, Deng B. A comparative analysis of the pedestrian injury risk predicted by mechanical impactors and post mortem human surrogates. Stapp Car Crash J 2008 Nov;52:527-67.

[25] Stoletzki N, Eyre-Walker A. Synonymous codon usage in Escherichia coli: selection for translational accuracy. Mol Biol Evol 2007 Feb;24(2):374-81.

[26] McNulty DE, Claffee BA, Huddleston MJ, Porter ML, Cavnar KM, Kane JF. Mistranslational errors associated with the rare arginine codon CGG in Escherichia coli. Protein Expr Purif 2003 Feb;27(2):365-74.

[27] Guo A, Cao S, Tu L, Chen P, Zhang C, Jia A, et al. FimH alleles direct preferential binding of Salmonella to distinct mammalian cells or to avian cells. Microbiology 2009 May;155(Pt 5):1623-33.

[28] Chan YG, Cardwell MM, Hermanas TM, Uchiyama T, Martinez JJ. Rickettsial outer-membrane protein $\mathrm{B}(\mathrm{rOmpB})$ mediates bacterial invasion through Ku70 in an actin, c-Cbl, clathrin and caveolin 2-dependent manner. Cell Microbiol 2009 Apr;11(4):629-44.

[29] Cardwell MM, Martinez JJ. The Sca2 autotransporter protein from Rickettsia conorii is sufficient to mediate adherence to and invasion of cultured mammalian cells. Infect Immun 2009 Dec;77(12):5272-80.

[30] Kim MK, Odgerel Z, Chung MH, Lim BU, Kang JS. Characterization of monoclonal antibody reacting exclusively against intracellular Orientia tsutsugamushi. Microbiol Immunol 2002;46(11):733-40.

[31] Wizemann TM, Adamou JE, Langermann S. Adhesins as targets for vaccine development. Emerg Infect Dis 1999 May;5(3):395-403. 
[32] Berrow NS, Bussow K, Coutard B, Diprose J, Ekberg M, Folkers GE, et al. Recombinant protein expression and solubility screening in Escherichia coli: a comparative study. Acta Crystallogr D Biol Crystallogr 2006 Oct;62(Pt 10):1218-26.

[33] Studier FW. Protein production by auto-induction in high density shaking cultures. Protein Expr Purif 2005 May;41(1):207-34.

[34] Kohler G, Milstein C. Continuous cultures of fused cells secreting antibody of predefined specificity. Nature 1975 Aug 7;256(5517):495-7.

[35] Renesto P, Dehoux P, Gouin E, Touqui L, Cossart P, Raoult D. Identification and characterization of a phospholipase D-superfamily gene in rickettsiae. J Infect Dis 2003 Nov 1;188(9):1276-83.
[36] Comstock LE, Fikrig E, Shoberg RJ, Flavell RA, Thomas DD. A monoclonal antibody to OspA inhibits association of Borrelia burgdorferi with human endothelial cells. Infect Immun 1993 Feb;61(2):423-31.

[37] Eremeeva ME, Roux V, Raoult D. Determination of genome size and restriction pattern polymorphism of Rickettsia prowazekii and Rickettsia typhi by pulsed field gel electrophoresis. FEMS Microbiol Lett 1993 Aug 15;112(1):105-12.

[38] Shevchenko A, Wilm M, Vorm O, Mann M. Mass spectrometric sequencing of proteins silver-stained polyacrylamide gels. Anal Chem 1996 Mar 1;68(5):850-8.

[39] Raoult D, Roussellier P, Vestris G, Tamalet J. In vitro antibiotic susceptibility of Rickettsia rickettsii and Rickettsia conorii: plaque assay and microplaque colorimetric assay. J Infect Dis 1987 May;155(5):1059-62. 